\title{
Effects of Electro-Acupuncture in Reducing Depression and Anxiety During Heroin withdrawal: A Randomized Controlled Trial
}

\author{
Liang Yan ${ }^{*}$, Weili Lu ${ }^{2}$, Zong Lei ${ }^{1}$, Lai Zhen ${ }^{1}, \mathrm{Ni} \mathrm{Gao}^{2}$ and Suchismita Ray \\ ${ }^{1}$ Yueyang Hospital of Integrated Traditional Chinese and Western Medicine, Shanghai University of Traditional Chinese Medicine, China \\ ${ }^{2}$ Rutgers University, USA
}

${ }^{3}$ Department of Health Informatics, Brain Health Institute, Rutgers Biomedical and Health Sciences, USA

Submission: January 05, 2019; Published: January 24, 2019

*Corresponding author: Liang Yan, Yueyang Hospital of Integrated Traditional Chinese and Western Medicine, Shanghai, China

\begin{abstract}
Opioid misuse and dependency are a public health crisis. This study examined the effectiveness of an electro-acupuncture intervention in reducing anxiety and depression among participants with heroin dependence experiencing withdrawal symptoms during detoxification stage. The data were from a randomized trial involving 60 adult clients of an adult drug detoxification program at a detention center in Shanghai, China. All participants had a diagnosis of heroin dependence. Participants were randomized to either five times a week, electro-acupuncture intervention lasting three weeks (totally 15 sessions) or a control group (no intervention). Hamilton Anxiety Rating Scale and Hamilton Depression Rating Scale were used to assess anxiety and depression at baseline, at one-week during treatment, at two-week during treatment, and at post-treatment (three weeks later). Treatment ended at three weeks later. Post treatment assessment was conducted. T-tests were used to assess the effectiveness of the intervention. The electro-acupuncture group improved more on anxiety symptoms than the control group (P<0.01). Electro-acupuncture intervention was found to be effective in reducing anxiety among participants going through detoxification stage of heroin dependence.
\end{abstract}

\section{Introduction}

Opioid misuse and dependency are a public health crisis. Opioid prescription rate between 1999 and 2010 has increased by an estimated $400 \%$ [1]. Opioid dependency and the rate of opioid-related overdoses have tripled since 2000, thus there exists the need for effective treatment methods [2,3]. Among individuals 12 and older in the United States, 4.5 million people reported using opioid prescriptions outside of medical use [4] This sharp increase in opioid prescription misuse has led to heroin abuse as users transition from prescription opioids to heroine [5]. Research has shown that those who use prescription opioids tend to use heroin in the future due to the accessibility and affordability [6].

Mortality rates involving opioid overdose, particularly opioid pain relievers and heroin, have tripled since 2000 [2] demonstrated two distinct but interrelated trends including a 15-year increase in overdose deaths involving prescription opioid pain relievers and a recent surge in illicit opioid overdose deaths, driven largely by heroin. Risks associated with opioid and heroin use included a $62 \%$ increase in motor vehicle collision risk, toxicity from the drugs themselves, infections from non-sterile needle use, HIV, hepatitis C, greater exposure to violence and traumatic injuries $[7,4]$. Compared to their non- user counterparts, chronic heroin users are reported to have a death rate 13 times higher, and chronic opioid users have a rate nearly 15 times higher [8,9]. Additionally, heroin users are 14 times more likely to die of suicide [8]. Interestingly, Cottler and colleagues found that many of the deaths occurred among those in treatment-seeking or treatment-attending individuals [4].

One common method of treatment for opioid use disorder is substitution medications such as methadone, suboxone, or naltrexone [10]. Numerous studies have been conducted to study the efficacy of drug substitution treatment, with most indicating positive results with long-term treatment. These studies support the idea that drug substitutes effectively mitigate withdrawal symptoms, promote treatment retention, and promote positive social activities [11]. Drug substitution treatment has been so well supported that the Obama administration proposed a \$1.1 billion proposal to further support use of suboxone to treat people with opioid addictions [10]. However, it must be taken into account that drug substitutes can lead to negative outcomes, such as methadone dependence and unintentional overdose [12]. Concomitant use of non-opioid drugs of those seeking treatment is another problem. Although opioid substitutes effectively block the effects of opioids that individuals seek, they 
do not block the effects of other drugs, such as cocaine, alcohol, and benzodiazepines [13].

Research is essential in understanding and evaluating treatment programs specific to opioid dependence and comorbidities [14]. More research may be conducted to determine the most appropriate and effective treatment programs to decrease opioid-related deaths and achieve satisfactory outcomes to improve daily functioning for individuals who have an opioid dependence [15]. Multiple factors contribute to relapse of those seeking treatment, including addiction syndrome, psychosocial factors, and treatment motivation [16]. Among them, Protracted Withdrawal Syndrome (PWS) is frequently found among opioids-dependent patients going through early detoxification. Protracted withdrawal, is defined as the presence of substancespecific signs and symptoms as well as the experience of nonsubstance-specific signs symptoms that persist, evolve, or appear well past beyond the generally expected initial timeframe for acute withdrawal. The most common symptoms are anxiety, depression, and sleep disturbances that can last for weeks or months. Other possible symptoms include fatigue, dysphoria (i.e., feeling down or emotionally blunted), irritability, decreased ability to focus on a task and deficits in executive control functions that may persist for months. The PWS significantly contribute to the relapses among opioids-dependent users while seeking treatment [17]. Therefore, interventions to cope with withdrawal symptoms are critical to relapse prevention and treatment success.

The effectiveness of acupuncture interventions for a variety of health problems have been established for a very long time [18]. Acupuncture is reported to increase serotonin production in the central nervous system, and thus reduce depression, anxiety and subjective distress among patients [19]. It also has been widely used in pain management $[20,21]$, the treatment of insomnia[22], stress urinary incontinence [23], the treatment of insomnia in major depressive disorders [24], and stroke $[25,26]$.

Electro-acupuncture is a type of acupuncture that combines both electric stimulation and acupuncture. It has been reported since 1970s, to reduce persistent withdrawal symptoms and prevent relapses, electro-acupuncture helps to improve psychiatric symptoms and anxiety and depression in methamphetamine addicted individuals during early detoxification and promote rehabilitation of patients [25,27-29]. Clinical experiments and case studies have confirmed its effectiveness in treating withdrawal symptoms among heroin users [30,31]. Patients reported relief from anxiety, agitation and depression, especially during the initial detoxification phase [32,33], as well as decrease in insomnia $[34,35]$. Studies [36] the changes of cognitive attention-related brain function in chronic heroin users during abstinence before and after electro-acupuncture intervention. Results showed that heroin users showed attention bias to heroin-related cues, which was significantly reduced by electro-acupuncture intervention, illustrating that electro-acupuncture could effectively inhibit the attention bias to heroin and thus can lowering the relapse rate. Electro-acupuncture thus reduces the physiological and psychological symptoms in heroin users and helps to manage withdrawal symptoms [37]. However, the evidence of application of Electro-acupuncture in reducing subjective distress such as depression and anxiety among individuals going through withdrawal symptoms during detoxification stage has not been systematically examined. Previous studies on Electro-acupuncture on PWS please (reviewers say: The authors should provide a comprehensive and in-depth review of previous studies on acupuncture for heroin withdrawal. What are the study designs in previous studies, what are the methodological limitations, and which heroin withdrawal symptoms can be helped by acupuncture? If there are no previous RCT, the first step should be a placebo- or sham-controlled RCT.). This study used a randomized controlled design to evaluate the effects of electro-acupuncture in reducing withdrawal symptoms including anxiety, subjective distress among 60 heroin-dependent clients in detoxification stage at a public treatment center for heroin addiction in Shanghai, China.

\section{Methods}

The randomized trial was conducted at an inpatient rehabilitation unit within a public treatment center for heroin addiction located in Shanghai, China. All study procedures were approved by the Yueyang Hospital of Integrated Traditional Chinese and Western Medicine (affiliated with the Shanghai University of Traditional Chinese Medicine) Institutional Review Board.

\section{Participants}

\section{Inclusion criteria for study participants were}

1. Meeting the diagnostic criteria of opiate dependence (ICD-10) during the classification of mental and behavior disorders which formulated by World Health Organization

2. Having heroin dependence for more than half a year, and the average daily usage was more than $0.5 \mathrm{~g}$

3. The age was between $18 \sim 60$ years old

4. Having received detox treatment for at least one week with withdrawal syndrome (including insomnia, depression, anxiety, body ache, coldness, joint pains, reduced appetite, constipation, increased heart rates)

5. Negative Morphine urine test

6. Not taking any psychotropic medication including methadone.

\section{Exclusion Criteria}

1. Serious heart disease, serious diseases of gastrointestinal tract (i.e., gastrorrhagia, stomach cancer, intestinal cancer, liver cancer), kidney failure, leukemia, and emphysema 
2. Having infectious disease, such as Hepatitis, AIDS, HIV

3. Pregnant and lactating women. The exclusion critiera are difficult to understand, e.g., what only exclude liver cancer? How about lung and other cancers? Why exclude those with infectious disease and GI problems?

A total of 60 participants provided written informed consent, completed baseline assessments, and were randomized to the Intervention program $(n=30)$ or the Control program $(n=30)$.

\section{Measures}

Research physicians assessed participant's severity of anxiety using the Hamilton Anxiety Rating Scale [38]. The 14item HARS questionnaire has two subscales - psychogenic and somatic anxiety. It measures somatic (muscular), somatic (sensory), cardiovascular, respiratory, gastrointestinal, genitourinary symptoms. The Somatic anxiety subscale measures muscular, sensory, cardiovascular, respiratory, gastrointestinal, genitourinary symptoms, and Psychogenic anxiety subscale assessing anxious mood, fears, depressed mood and insomnia. Every HARS's item is rated on a 5-point Likert scale, ranging from 0 (not present) to 4 (severe). Participants were assessed at baseline, at one-week during treatment, at two-week during treatment and at post-treatment (3 weeks later). In addition, research physicians provided ratings of depression using the Hamilton Depression Rating Scale [38]. The 21-item HDRS questionnaire is rated on a 5-point likert scale, ranging from 0 (not present) to 4 (severe).

\section{Treatment programs}

\section{Electro-acupuncture intervention $(n=30)$}

The physicians specializing in Acupuncture followed a standard treatment protocol. The acupuncture needles were placed on 12 acupuncture points in bilateral arms and legs, with six acupuncture points on one side of the body [Nei-guan P6, Shenmen H7, Foot Three Li (near the knee), San-yin-jiao SP6 (near the foot ankle) bilateral Huatuo Jaji points and Renal Shu]. (What are the reasons for choosing acupoints?. The constant current square-wave electric-stimulation was produced by an EA apparatus (Model G6805-2). The frequency of stimulation used was 3 5 Hz, rare wave.(WHY 3-5 Hz stimulation). The highest intensity of the stimulation was $5 \mathrm{~Hz}$. Each session lasted for 20 minutes, consistent with Zeng and colleagues [15]. The intervention was provided once a day, five times a week for 3 weeks. (Why each session lasts 20 minutes and 5 times a week?). The participants also received regular services provided at the inpatient unit, including regular breaks in the afternoon for about one hour, arts and crafts group. Psychological services such as individual counseling, Narcotic Anonymous (NA) groups, and group counseling were not provided [39-44].

\section{Treatment as usual group $(n=30)$}

The treatment as usual group received regular services provided at the inpatient unit. The services included regular breaks in the afternoon for about an hour, arts and crafts group. Psychological services such as individual counseling, NA groups, and group counseling were not provided.

\section{Procedures}

\section{Recruitment}

Patients were given information about the study and were referred to the study team if they met preliminary eligibility criteria for the study. Potentially eligible patients were contacted by the research team, who described the study and obtained informed consent. The baseline assessment was conducted to confirm eligibility, with persons meeting all criteria randomized to either the Electro-Acupuncture group or the treatment as usual group.

\section{Randomization}

Participants were randomized to the treatment group or control group via random numbers. Sixty participants were randomized into two groups, with 30 participants in the electroacupuncture group; and 30 in the treatment as usual group.

\section{Assessment Timeline}

Clinical assessments were conducted at baseline, at oneweek during treatment, at two-week during treatment, and at post-treatment (3 weeks later).

\section{Results}

Table 1: Baseline Characteristics by Treatment Group.

\begin{tabular}{|c|c|c|c|c|c|}
\hline \multirow{2}{*}{$\begin{array}{c}\text { Charac- } \\
\text { teristic }\end{array}$} & \multicolumn{2}{|c|}{ TAU (N=30) } & \multicolumn{3}{|c|}{ Acupuncture(N=30) } \\
\cline { 2 - 6 } & $\begin{array}{c}\text { n or } \\
\text { mean }\end{array}$ & \% or sd & $\begin{array}{c}\text { n or } \\
\text { mean }\end{array}$ & \% or sd & P \\
\hline $\begin{array}{c}\text { Gender, } \mathrm{n} \\
\text { (\%) }\end{array}$ & 21 & 70 & 20 & 67 &.$>.05$ \\
\hline Male & 30 & 10 & 33 & \\
\hline Female & 9 & 9.41 & 33.77 & 9.24 & $>.05$ \\
\hline $\begin{array}{c}\text { Age, } \\
\text { mean(sd) }\end{array}$ & 32.6 & 44.65 & 55.37 & 48.85 & $>.05$ \\
\hline $\begin{array}{c}\text { Length } \\
\text { of Heroin } \\
\text { Use } \\
\text { (Months) }\end{array}$ & 60.53 & 0.6 & 1.2 & 0.8 & $>.05$ \\
\hline $\begin{array}{c}\text { Amount } \\
\text { of Aver- } \\
\text { age Use } \\
\text { Per Day }\end{array}$ & 1.1 & & & & \\
\hline
\end{tabular}

Note: TAU = Treatment as Usual; Continuous variables were analyzed using one-way ANOVA. Gender was analyzed using chi-square test.

The characteristics of the two study groups are summarized in Table 1 . The average age was 34.28 years old. The average educational level was 9.20; $41.7 \%$ participants were married, $20.0 \%$ were single, and $38.3 \%$ were divorced. Methods of drug use were snorting (53.3\%), intravenous injection (30.0\%), and injection and snorting both $(16.7 \%)$. The range of time in 
abusing Heroin was 6 222 months. The average heroin-using time was $64.94 \pm 52.73$ months. The daily usage of heroin use was $0.5 \mathrm{~g} \sim 4.5 \mathrm{~g}$ per day, with a mean of $1.17 \mathrm{~g}$ per day. The average frequency of usage times was 1 8 times per day. Comparisons of the two groups at baseline indicated no significant difference (Table 1). Participants in two groups did not differ on age, gender, length of Heroin use, and average amount of daily use. Approximately, one third of the sample were female, while two thirds of the sample were male. Participants were in their $30 \mathrm{~s}$ on average. Participants varied in the length of Heroin use, with an average length of 50-60 months, averaging four years to five years of history of Heroin use. The average amount of use was approximately 1.17 grams per day.

\section{Engagement and Treatment Outcome}

Engagement in treatment programs was high, with 30 (100\%) participants completing 15 sessions of acupuncture in the time span of three weeks. The analyses of the other outcomes indicated significant group effects, with the electro-acupuncture group improving more than the control group on HDRS, HARS total anxiety scale, HARS psychogenic anxiety and HARS somatic anxiety (Table 2). The effect sizes for treatment effect were large for depression (HDRS, range 1.15 to 2.52), total anxiety (HARS, range 1.69 to 2.39), large for HDRS subscale of psychogenic anxiety (2.27 to 2.39) and moderate too large for HARS subscale of somatic anxiety ( 0.89 to 1.55 ).

Table 2: Comparison of Acupuncture Group and Control Group in Anxiety Before, During and After Treatment.

\begin{tabular}{|c|c|c|c|c|c|c|c|}
\hline & \multicolumn{2}{|c|}{ TAU } & \multicolumn{2}{|c|}{ Acupuncture } & \multirow[b]{2}{*}{$\mathbf{t}$} & \multirow[b]{2}{*}{$\mathbf{P}$} & \multirow[b]{2}{*}{ ES } \\
\hline & $\mathbf{M}$ & SD & $\mathbf{M}$ & SD & & & \\
\hline \multicolumn{8}{|c|}{ HARS total } \\
\hline Baseline & 23 & 3.49 & 23.27 & 5.43 & 0.23 & $>.05$ & NA \\
\hline 1-week & 17.36 & 3.93 & 10.7 & 3.59 & -6.85 & $<.01$ & -1.69 \\
\hline 2-week & 14.25 & 4.05 & 4.57 & 1.87 & -11.89 & $<.01$ & -2.39 \\
\hline 3-week & 11.93 & 4.05 & 2.53 & 1.61 & -11.81 & $<.01$ & -2.32 \\
\hline \multicolumn{8}{|c|}{ Subscale Psychogenic Anxiety } \\
\hline Baseline & 12.82 & 3.27 & 12.43 & 2.73 & -0.51 & $>.05$ & -0.12 \\
\hline 1-week & 11.21 & 2.64 & 6.87 & 2.08 & -7.07 & $<.01$ & -1.64 \\
\hline 2-week & 9.36 & 2.38 & 3.67 & 1.65 & -10.76 & $<.01$ & -2.39 \\
\hline 3-week & 8.18 & 2.53 & 2.17 & 1.58 & -11.04 & $<.01$ & -2.38 \\
\hline \multicolumn{8}{|c|}{ Subscale Somatic Anxiety } \\
\hline Baseline & 10.11 & 1.83 & 10.83 & 3.82 & 0.93 & $>.05$ & 0.39 \\
\hline 1-week & 6.14 & 2.49 & 3.9 & 2.26 & -3.65 & $<.01$ & -0.9 \\
\hline 2-week & 4.89 & 2.57 & 0.9 & 1.06 & -7.86 & $<.01$ & -1.55 \\
\hline 3-week & 3.75 & 2.19 & 0.37 & 0.67 & -8.08 & $<.01$ & -1.54 \\
\hline \multicolumn{8}{|c|}{ HDRS total } \\
\hline Baseline & 29.93 & 3.81 & 29.47 & 3.43 & -0.49 & $>.05$ & NA \\
\hline 1-week & 22.43 & 5.10 & 16.57 & 4.64 & -4.66 & $<.01$ & -1.15 \\
\hline 2-week & 19.14 & 5.09 & 7.77 & 3.39 & -10.18 & $<.01$ & -2.23 \\
\hline 3-week & 16.32 & 4.73 & 4.40 & 2.63 & -12.06 & $<.01$ & -2.52 \\
\hline
\end{tabular}

\section{Discussion}

This is the first randomized control trial of an electroacupuncture intervention tailored for individuals with heroin dependence going through withdrawal symptoms. It examined the effectiveness of the acupuncture intervention in reducing anxiety from withdrawal symptoms as compared with the as usual detox treatment. The effect sizes of treatment were in the large range for depression, as well as for anxiety. Individuals of control group had reduced depression as time in detoxification continued, from 29 points to 16 points on depression rating scale. Those receiving electro-acupuncture had depression from 29 points to 4 points on depression rating scale. Individuals of control group also had reduced anxiety, from 23 points to
11 points, while those receiving intervention reduced from 23 points to 2 points. The effect sizes of treatment were mostly in the large range for anxiety.

The results of this study indicate that those receiving Electroacupuncture improved significantly in having less anxiety and depression than those without acupuncture. Results indicate that the Acupuncture treatment has a short-term effect in reducing subjective suffering and as a result, it may increase the chance of recovery for persons with heroin dependence experiencing withdrawal symptoms, then they would have been in the absence of such intervention. This study has several limitations. The study did not control for expectancy effect (placebo response) and assessment bias. There was no comparison with 
active non-drug treatment condition such as comparison with psychotherapy condition. Future studies should use a sham treatment condition to control placebo effect, use a non-drug active treatment condition as a comparison group, and use assessors blind to treatment condition. The study only found a short-term effect of acupuncture and its effectiveness for PWS is unclear. We caution that this study's results were obtained from Chinese ethnic group, and that the results may not generalize to other ethnic groups, or to individuals with other substance use disorders, or to those with comorbid mental illnesses. Future studies on Acupuncture for different ethnic groups, and for individuals with comorbid heroin dependence and heroin abuse may be indicated.

\section{Conclusion}

In a sample of Chinese adults with heroin dependence, the electro-acupuncture intervention was found to be effective than no intervention in reducing depression and anxiety among participants going through detoxification from Heroin abuse. The results were fast seen at first week after treatment and patients continued to improve as treatment progressed until three weeks later. Results indicate that the intervention may reduce withdrawal symptoms for this population. More evidence regarding the acupuncture intervention's effectiveness for Opioid abuse is needed to address this question.

\section{Acknowledgements}

We are grateful to the staff and participants at the Institute of Rehabilitation for Drug Addiction at Shanghai Public Security Bureau.

\section{Research Funding}

Funding from the National Science Foundation of China (\#81403473) from the Shanghai Bureau of Health (\#20134292), and from the National Institute on Drug Abuse (NIH/NIDA R03DA044496) is gratefully acknowledged.

\section{References}

1. Paulozzi LJ, Jones CM, Mack KA, RuddRA (2011) Vital signs: Overdoses of prescription opioid pain relievers -United States, 1999-2008. Morbidity and Mortality Weekly Report 60(43): 1487-1492.

2. Rudd RA, Aleshire N, Zibbell JE, Gladden RM (2016) Increases in Drug and Opioid Overdose Deaths-United States, 2000-2014. American Journal of Transplantation 16(4): 1323-1327.

3. Guy GP, Zhang K, Bohm MK, Losby J, Lewis B, et al. (2017) Vital signs: Changes in opioid prescribing in the United States, 2006-2015. MMWR: Morbidity \& Mortality Weekly Report 66(26): 697-704.

4. Cottler LB, Hu H, Smallwood BA, Anthony JC, Wu L, et al. (2016) Nonmedical opioid pain relievers and all-cause mortality: A 27-year follow-up from the epidemiologic catchment area study. Am J Public Health 106(3): 509-516.

5. Jones CM (2013) Heroin use and heroin use risk behaviors among nonmedical users of prescription opioid pain relievers-United States, 2002-2004 and 2008-2010. Drug Alcohol Depend 132(1-2): 95-100.

6. Cicero TJ, Ellis MS, Surratt HL, Kurtz SP (2014) The changing face of heroin use in the United States. JAMA Psychiatry 71(7): 821-826.
7. Wickens CM, Mann RE, Ialomiteanu AR, Rehm J, Fischer B, et al. (2017) The impact of medical and non-medical prescription opioid use on motor vehicle collision risk. Transportation Research Part F: Traffic Psychology and Behaviour 47: 155-162.

8. Darke S, Ross J (2002) Suicide among heroin users: rates, risk factors and methods. Addiction 97(11): 1383-1394.

9. Larney S, Bohnert AS, Ganoczy D, Ilgen MA, Hickman M, et al. (2015) Mortality among older adults with opioid use disorders in the Veterans Health Administration, 2000-2011. Drug and Alcohol Deped 147: 3237.

10. Park A (2016) A new paradigm for opioid addiction: More drugs Time 188(16-17): 48.

11. Fiellin DA, Friedland GH, Gourevitch MN (2006) Opioid dependence: Rationale for and efficacy of existing and new treatments. Clinical Infectious Diseases 43(4): S173-S177.

12. Jones CM, Baldwin GT, Manocchio T, White JO, Mack KA (2016) Trends in methadone distribution for pain treatment, methadone diversion, and overdose deaths- United States, 2002-2014. MMWR: Morb Wkly Rep 65(26): 667-671.

13. Bell J (2014) Pharmacological maintenance treatments of opiate addiction. Br J Clin Pharmacol 77(2): 253-263.

14. Brady KT, McCauley JL, Back SE (2016) Prescription opioid misuse, abuse, and treatment in the United States: An update. Am J Psychiatry 173(1): 18-26.

15. Rosenblum A, Marsch LA, Joseph H, Portenoy RK (2008) Opioids and the treatment of chronic pain: Controversies, current status, and future directions. Experimental and Clinical Psychopharmacology 16(5): 405416.

16. Tasić JK, Valkanou MK, Đukanović B, Banković D, Janjić V (2017) Relapse Risk Factors in Heroin Addicts Treated with Naltrexone and Naltrexone Behavioural Psychotherapy. International Journal of Mental Health and Addiction.

17. Samhsa (2010) Substance Abuse and Mental Health Services Administration.

18. Wu JN (1996) A short history of acupuncture. J Altern Complement Med 2(1): 19-21.

19. Karatay S, Okur SC, Uzkeser H, Yildirim K, Akcay F (2017) Effects of acupuncture treatment on fibromyalgia symptoms, serotonin, and substance p levels: A randomized sham and placebo-controlled clinical trial. Pain Med 19(3): 615-628.

20. Hurtak JJ (2002) An overview of acupuncture medicine. J Altern Complem Med 8(5): 535-538.

21. Lee H, Ernst E (2005) Acupuncture analgesia during surgery: a systematic review Pain 114(3): 511-517.

22. Fu C, Zhao N, Liu Z, Yuan LH, Xie C, et al. (2017) Acupuncture improves peri-menopausal insomnia: A randomized controlled trial. Sleep $40(11)$.

23. Liu Z, Liu Y, Xu H, He L, Chen Y, et al. (2017) Effect of electroacupuncture on urinary leakage among women with stress urinary incontinence: A randomized clinical trial. JAMA 317(24): 2493-2501.

24. Yeung WF, Chung KF, Tso KC, Zhang SP, Zhang ZJ, et al. (2011) Electroacupuncture for residual insomnia associated with major depressive disorder: a randomized controlled trial. Sleep 34(6): 807815.

25. Hu A, Lai M, Wei J, Wang L, Mao H, et al. (2013) The effect of electroacupuncture on extinction responding of heroin-seeking behavior and FosB expression in the nucleus accumbens core. Neurosci Lett 534: 252-257. 
26. Jansen G, Lundeberg T, Kjartansson J, Samuelson UE (1989) Acupuncture and sensory neuropeptides increase cutaneous blood flow in rats. Neurosci Lett 97(3): 305-309.

27. Clement Jones V, McLoughlin L, Lowry PJ, Besser GM, Rees LH, et al (1979) Acupuncture in heroin addicts; changes in met-enkephalin and beta-endorphin in blood and cerebrospinal fluid. Lancet 2(8139): 380 338

28. Chan YY, Lo WY, Li TC, Shen LJ, Yang SN, et al. (2014) Clinical efficacy of acupuncture as an adjunct to methadone treatment services for heroin addicts: a randomized controlled trial. Am J Chin Med 42(3): 569-586.

29. Zeng L, Ying T, Wenguang H, Zong L, Yu L (2018) Electro-acupuncture improves psychiatric symptoms, anxiety and depression in methamphetamine addicts during abstinence. Medicine 97(34): e11905.

30. Wen HL (1977) Fast detoxification of heroin addicts by acupuncture and electrical stimulation (AES) in combination with naloxone. Comp Med East West 5(3-4): 257-263.

31. Wen HL, Ho WK (1982) Suppression of withdrawal symptoms by dynorphin in heroin addicts. Eur J Pharmacol 82(3-4): 183-186.

32. Zhang B, Yang C, Ke C, Xueyong S, Sheng L (2014) Efficacy of acupuncture for psychological symptoms associated with opioid addiction: a systematic review and meta-analysis. Evid Based Complement Alternat Med 2014: 313549.

33. Hou WG, Liang Y, Wang YX, Zong L, Chen YA (2009) Clinical observation of electro-acupuncture intervention on depression of heroin addicts after withdrawal. Chin J Drug Abuse Prev Treat 15: 11-13.

34. Zong L, Hou W, Wang X, An B (2009) Effects of acupuncture on insomnia among heroin addicts. Shanghai Journal of Acupuncture 4: 191-194.
35. Zhu Z, Mu J, Liang Y, Zong L, Hu J, et al. (2005) Clinical observation on sleep disturbance after using electro-acupuncture among heroin dependent individuals. Shanghai Journal of Acupuncture 5: 6-8.

36. Jiang YP, Liu H, Xu P, Wang Y, Lu GH (2011) Effect of electro-acupuncture on cognition attention bias in heroin addiction abstinence-a dot-probebased event-related potential study. Chinese Journal of Integrative Medicine 17(4): 267-271.

37. Hamilton M (1959) The assessment of anxiety states by rating. Br J Med Psychol 32(1): 50-55.

38. Hamilton M (1980) Rating depressive patients. Journal of Clinical Psychiatry 41(12): 21-24.

39. Clark RE, Ricketts SK, McHugo GJ (1996) Measuring hospital use without claims: a comparison of patient and provider reports. Health Services Research 31(2): 153-169.

40. Florence CS, Zhou C, Luo F, Xu L (2016) The economic burden of prescription opioid overdose, abuse, and dependence in the United States 2013. Med Car 54(10): 901-906.

41. Hsu DJ, Mccarthy EP, Stevens JP, Mukamal KJ (2017) Hospitalizations, costs and outcomes associated with heroin and prescription opioid overdoses in the United States 2001-12. Addiction 112(9): 1558-1564.

42. Mark TL, Woody GE, Juday T, Kleber HD (2001) The economic costs of heroin addiction in the United States. Drug and Alcohol Depend 61(2): 195-206.

43. Red Book: Pharmacy's Fundamental Reference (2011) Montvale, NJ: Truven Health Analytics.

44. Wu S, Leung A, Yew D (2016) Acupuncture for detoxification in treatment of opioid addiction. East Asian Arch Psychiatry 26 (2): 7076.

\section{Your next submission with Juniper Publishers will reach you the below assets}

- Quality Editorial service

- Swift Peer Review

- Reprints availability

- E-prints Service

- Manuscript Podcast for convenient understanding

- Global attainment for your research

- Manuscript accessibility in different formats

( Pdf, E-pub, Full Text, Audio)

- Unceasing customer service

Track the below URL for one-step submission https://juniperpublishers.com/online-submission.php 